\title{
The Viewpoint of Community Pharmacists about Their Professional Role in Dispensing Beauty Products: A Study from Western Region of Saudi Arabia
}

\author{
Ali Mofleh Alshahrani, Taghreed Mubarak Alotaibi, Nawal Safar Alrabie, \\ Bashayer Mohammed Althobaiti, Fatimah Nasser Alshelawi, Maram Abdullah Althobaiti, \\ Mona Yaser Alsheikh, Ahmed Ibrahim Fathelrahman*
}

Department of Clinical Pharmacy, College of Pharmacy, Taif University, Taif, Kingdom of Saudi Arabia

Email: *afathelrahman@yahoo.com

How to cite this paper: Alshahrani, A.M. Alotaibi, T.M., Alrabie, N.S., Althobaiti, B.M., Alshelawi, F.N., Althobaiti, M.A., Alsheikh, M.Y. and Fathelrahman, A.I. (2021) The Viewpoint of Community Pharmacists about Their Professional Role in Dispensing Beauty Products: A Study from Western Region of Saudi Arabia. Pharmacology \& Pharmacy, 12, 63-72.

https://doi.org/10.4236/pp.2021.123006

Received: February 7, 2021

Accepted: March 19, 2021

Published: March 22, 2021

Copyright $\odot 2021$ by author(s) and Scientific Research Publishing Inc. This work is licensed under the Creative Commons Attribution International License (CC BY 4.0).

http://creativecommons.org/licenses/by/4.0/

\begin{abstract}
Background: Community pharmacists play a significant role in dispensing and counseling about medications and pharmaceuticals including beauty and cosmetic products. Aims and Objectives: The current study was conducted to assess the viewpoint of community pharmacists in the Western region of Saudi Arabia about their professional role in dispensing beauty products. Methods: A cross-sectional study was conducted between September and December 2019 using an online questionnaire. Expert professors from college of pharmacy, Taif University validated the questionnaire. Results: Five hundred seventy-seven community pharmacists completed the questionnaire. Most of the participants were male (99\%) and aged 23 - 34 years old (71.1\%). Slightly less than half (45.58\%) of community pharmacists have $6-10$ years of experience. Most pharmacists (96.9\%) communicate directly with customers/ patients and most of them (85.3\%) ask and counsel patients about their product. Pharmacists strongly agreed that pharmacists must keep in developing their communication skills with customers/patients. Conclusion: Most of the community pharmacists surveyed in this study reported a good perceived knowledge and attitudes and demonstrated an acceptable level of practices regarding beauty products. Saudi FDA is encouraged to adopt Good Pharmacy Practice standards and guidelines to improve current practice of community pharmacists concerning Beauty Products.
\end{abstract}

\section{Keywords}

Community Pharmacies, Pharmacists, Beauty Products, Cosmetics, 
Saudi Arabia

\section{Introduction}

Pharmacists play a complementary role to other health care professionals. They counsel patients about appropriate use of medications and serve them optimizing therapy [1]. A study conducted in the western region of Saudi Arabia revealed a high willingness among young residents to receiving medication therapy management services from community pharmacists [2].

A study among community pharmacists in Saudi Arabia indicated that effective clinical services inbound with knowledge, need, value and confidence of the pharmacists [3].

One of the common areas that require an effective contribution of community pharmacists and their direct involvement is the area of cosmetics and beauty products. It is, however, an ignored area regarding offering standardized quality service. A study in Riyadh assessed the information presented in print pharmaceutical advertisements and indicated that safety information related to side effects, precautions, and major interactions was inadequately reported in examined advertising materials [4]. Another study conducted in Riyadh, Saudi Arabia revealed presence of deficiencies in appropriate dispensing practices and medication counselling at community pharmacies [5]. A study performed at Qassim region, Saudi Arabia evaluated the medication counselling practice at community pharmacies and revealed that overall standard of medication counseling services provided to patients to improve usage of their medications, and consequently, their well-being was poor [6].

Rasheed et al. conducted a systematic review on 24 studies addressing community pharmacist's knowledge, attitude, roles and practices towards patient-centred care in Saudi Arabia [7]. Although such studies addressed various issues and topics across the broad array of practice none evaluated the role of community pharmacists in controlling beauty product sale. However, a recent study not covered by the previous review explored the pharmacists' knowledge and attitude towards cosmeceuticals in Saudi Arabia [8]. The study targeted registered pharmacists in different sectors in Saudi Arabia and its findings indicated a need for increasing the awareness of pharmacist in such area of practice. Another study from Iran indicted insufficiency of pharmacist information about some types of cosmetics [9].

To our knowledge, no reports are available evaluating current practices in community pharmacies regarding beauty products in the Western region, Saudi Arabia. This is what we attend to investigate in our study.

\section{Study Objective}

This study was conducted to assess the viewpoint of community pharmacists in the Western region of Saudi Arabia about their professional role in dispensing 
beauty products.

\section{Methods}

\subsection{Study Design}

A cross-sectional study was conducted between September and December 2019 using an online questionnaire.

\subsection{Population}

The survey targeted community pharmacists all over Saudi Arabia and current analysis includes the pharmacists from Western region of the country. The Western region of Saudi Arabia geographically includes the two administrative regions Makkah and Al Madinah. Makkah region includes the big cities of Taif, Makkah and Jeddah besides others.

\subsection{Inclusion Criteria}

All Saudi and non-Saudi community pharmacists from the Western region of Saudi Arabia from both genders were included in this study.

\subsection{The Questionnaire}

The questionnaire was developed specifically for the purpose of the current study. It was used to elicit the community pharmacists' answers on different variables addressing the study objectives. It comprised four parts: demographic characteristics, knowledge, perceptions, and practice. Expert professors from college of pharmacy, Taif University validated the questionnaire for the face and contents. They have been asked to provide feedback on comprehensiveness of contents, consistency of measured items, overall length, redundancy of items and any required editing. The drafted questionnaire has been modified according to the reviewers' suggestions. They concluded that questions in the finalized version were clear-cut, easy to understand (for the potential respondents), and that the choice of answers accurately capture the opinions of the potential respondents.

\subsection{Study Procedure}

The sampling was convenient sampling technique. The questionnaire was designed to be administered online using Google forms. The survey link was distributed firstly to pharmacists' professional groups via social media like WhatsApp and secondly through key persons in the large pharmaceutical groups in the country.

\subsection{Sample Size}

According to AlRuthia et al., the number of community pharmacists in Saudi Arabia is 8419 representing $34.5 \%$ of 24,395 licensed pharmacists working in different sectors [10]. By administrative provinces, there are 6100 and 1132 
pharmacists working in different sectors in Makkah and Al Madinah, respectively (i.e., 7232 pharmacists in Western region representing $29.6 \%$ of all licensed pharmacy workforce in the country). Extrapolating such statistics reveals an expectation of about 2495 pharmacists working in the community pharmacies through whole Western region. In such context, we judged that surveying at least 250 pharmacists from the Western region would be representative (i.e., $10 \%)$.

\subsection{Ethical Consideration}

Ethical approval was obtained from the research and ethics committee at Taif University (Reference number: 41-35-0028). Informed consent was obtained from all participants before commencing the study.

\subsection{Data Analysis}

Data was analyzed descriptively using SPSS software. Each section included qualitative and quantitative variables. Findings regarding qualitative variables were presented as frequencies and percentages, whereas that related to quantitative ones were presented as means (standard deviation).

\section{Results}

\subsection{Demographic Characteristics}

Five hundred seventy-seven community pharmacists completed the questionnaires. Table 1 shows their demographic characteristics. Most of them were men (99\%), non-Saudi (94.6\%), aged between 23 and 34 years (71.06\%), and were bachelor's degree holders (85.44\%). Most of them were from Makkah (84.1\%) and few were from Al Madinah (15.94\%). Regarding experience, slightly less than half (45.58\%) of the respondents have $6-10$ years and fewer proportions with lower or higher length of experiences. The average self-rating of job satisfaction on 5 points Likert scale was 3.82 (St.D. $=0.97$ ).

\subsection{Knowledge}

Most of respondents $(80.07 \%)$ declared undertaking courses about cosmetic and personal care products (Table 2), and about half of them received more than 5 courses. On average, they rated their knowledge about cosmetic and personal care products on 5 points Likert scale to be high (average score $=4.14$, St.D. $=$ 0.66). Awareness about Saudi Food and Drug Authority (SFDA) regulations of "cosmetic and personal care products" was rated also high (average score $=3.57$, St.D. $=0.99)$.

\subsection{Perceptions}

Most of respondents (93.1\%) considered customers/patients counseling on cosmetics and personal care products as important (Table 3). Three perception-related statements were rated by respondents on 5 points Likert scale. The 
statement which was rated highest was "pharmacists must keep in developing their communication skills with customers/patients" (average score $=4.59$, St.D. $=0.93$ ), followed by the statement "customers/patients are willing to listen to the counseling about their products" (average score $=3.96$, St.D. $=0.94$ ), then the statement "support the idea of selling cosmetics and personal care products in other places than community pharmacies" (average score $=2.08$, St.D. $=1.26$ ). The later statement was rated low with a high variation among pharmacists in rating (i.e. standard deviation high).

Table 1. Demographic characteristics of respondent pharmacists. (a) Categorical variables; (b) Quantitative variables.

(a)

\begin{tabular}{|c|c|}
\hline Characteristics & Frequency (\%) \\
\hline \multicolumn{2}{|l|}{ Age (Years) } \\
\hline 23 - 34 years. & $410(71.1)$ \\
\hline $35-44$ years & $154(26.7)$ \\
\hline 45 - 54 years & $13(2.2)$ \\
\hline \multicolumn{2}{|l|}{ Gender } \\
\hline Male & $571(99.0)$ \\
\hline Female & $6(1.0)$ \\
\hline \multicolumn{2}{|l|}{ Nationality } \\
\hline Saudi & $31(5.4)$ \\
\hline Non-Saudi & $546(94.6)$ \\
\hline \multicolumn{2}{|l|}{ Region } \\
\hline Al Madinah & $92(15.9)$ \\
\hline Makkah $^{\star}$ & $485(84.1)$ \\
\hline \multicolumn{2}{|l|}{ Qualification } \\
\hline Diploma & $7(1.2)$ \\
\hline Bachelor & $493(85.4)$ \\
\hline PharmD & $73(12.7)$ \\
\hline Master & $4(0.7)$ \\
\hline \multicolumn{2}{|l|}{ Professional classification } \\
\hline Pharmacist & $449(77.8)$ \\
\hline Senior pharmacist & $118(20.5)$ \\
\hline Consultant pharmacist & $10(1.7)$ \\
\hline \multicolumn{2}{|l|}{ Years of experience } \\
\hline$<2$ years & $17(2.9)$ \\
\hline $2-5$ years & $106(18.3)$ \\
\hline $6-10$ years & $263(45.6)$ \\
\hline$>10$ years & $191(33.1)$ \\
\hline \multicolumn{2}{|l|}{ Board-certification } \\
\hline Yes & $151(26.2)$ \\
\hline No & $426(73.8)$ \\
\hline \multicolumn{2}{|l|}{ Receiving a clinical training } \\
\hline Yes & $136(23.6)$ \\
\hline No & $441(76.4)$ \\
\hline
\end{tabular}

* Makkah region includes the cities of Makkah, Taif and Jeddah.

(b)

\begin{tabular}{cc}
\hline Variable & Score (St. D.) \\
\hline Self-rating of Job satisfaction on 5 points scale $($ mean \pm SD) & $3.82(0.97)$ \\
\hline
\end{tabular}


Table 2. Beauty products-related knowledge of respondent pharmacists. (a) Categorical variables; (b) Quantitative variables.

(a)

\begin{tabular}{|c|c|}
\hline Variable & Frequency (\%) \\
\hline \multicolumn{2}{|l|}{ Have you ever taken any course about cosmetic and personal care products? } \\
\hline No & $115(19.93)$ \\
\hline Yes & $462(80.07)$ \\
\hline \multicolumn{2}{|l|}{ How many cosmetic courses have you got? } \\
\hline 0 & $1(0.22)$ \\
\hline 1 & $63(13.64)$ \\
\hline $2-3$ & $99(21.43)$ \\
\hline $4-5$ & $43(9.31)$ \\
\hline$>5$ & $256(55.41)$ \\
\hline \multicolumn{2}{|l|}{ (b) } \\
\hline Variable & Score (St. D.) \\
\hline $\begin{array}{l}\text { Self-rating of knowledge about cosmetics } \\
\text { and personal care products on } 5 \text { points scale }(\text { mean } \pm \text { SD) }\end{array}$ & $4.14(0.66)$ \\
\hline $\begin{array}{l}\text { Self-rating of knowledge about Saudi Food and Drug Authority (SFDA) } \\
\text { regulations of cosmetic and personal care products on } 5 \text { points scale (mean } \pm \text { SD) }\end{array}$ & $3.57(0.99)$ \\
\hline
\end{tabular}

Table 3. Beauty products-related perceptions of respondent pharmacists. (a) Categorical variables; (b) Quantitative variables.

(a)

\begin{tabular}{|c|c|}
\hline Variable & Frequency (\%) \\
\hline \multicolumn{2}{|l|}{$\begin{array}{c}\text { The importance of customers/patients counseling on cosmetics and } \\
\text { personal care products. }\end{array}$} \\
\hline Not important & $2(0.3)$ \\
\hline Not sure & $2(0.3)$ \\
\hline It depends on the products. & $36(6.2)$ \\
\hline Yes important & $537(93.1)$ \\
\hline \multicolumn{2}{|l|}{ (b) } \\
\hline Variable & Score (St. D.) \\
\hline $\begin{array}{l}\text { Pharmacists must keep in developing their communication skills with } \\
\text { customers/patients (mean } \pm \text { SD) }\end{array}$ & $4.59(0.93)$ \\
\hline $\begin{array}{l}\text { Customers / patients are willing to listen to the counseling about their products } \\
\qquad(\text { mean } \pm \text { SD) }\end{array}$ & $3.96(0.94)$ \\
\hline $\begin{array}{l}\text { Support the idea of selling cosmetics and personal care products in other places } \\
\text { than community pharmacies (mean } \pm \text { SD) }\end{array}$ & $2.08(1.26)$ \\
\hline
\end{tabular}

\subsection{Practices}

Table 4 shows the beauty products-related practice. Most of pharmacists communicate with customers/patients directly via face-to-face (96.9\%), serve daily more than 100 customers/patients (62.4\% of pharmacists), and substantial proportion of them ( $>20$ patients for $54.1 \%$ of pharmacists) are asked for cosmetic or personal care products. Most of respondents ask the customers/patients if they have sensitivity from any components in the product (85.3\%) and use both 
Table 4. Beauty products-related practice of respondent pharmacists. (a) Categorical variables; (b) Quantitative variables.

(a)

\begin{tabular}{|c|c|}
\hline Variable & Frequency $(\%)$ \\
\hline \multicolumn{2}{|l|}{ How do you communicate with customers/patients? } \\
\hline Direct (Face to face) & $559(96.9)$ \\
\hline Indirect (Telephone - Email - medical brochures) & $13(2.2)$ \\
\hline No communication & $5(0.9)$ \\
\hline \multicolumn{2}{|l|}{ How many customers/patients do you serve daily? } \\
\hline$<50$ & $30(5.2)$ \\
\hline $50-100$ & $187(32.4)$ \\
\hline$>100$ & $360(62.4)$ \\
\hline \multicolumn{2}{|l|}{ How many of them ask for cosmetic or personal care products? } \\
\hline$<10$ & $28(4.8)$ \\
\hline 10 to 15 & $107(18.5)$ \\
\hline 16 to 20 & $130(22.5)$ \\
\hline$>20$ & $312(54.1)$ \\
\hline \multicolumn{2}{|l|}{$\begin{array}{l}\text { Do you ask the customers/patients if they have sensitivity from any components } \\
\text { in the product? }\end{array}$} \\
\hline Yes & $492(85.3)$ \\
\hline No & $85(14.7)$ \\
\hline \multicolumn{2}{|l|}{ Do you use generic name, brand name or both during dispensing process? } \\
\hline Generic name & $23(4.0)$ \\
\hline Brand name & $95(16.5)$ \\
\hline Both & $459(79.5)$ \\
\hline \multicolumn{2}{|l|}{ (b) } \\
\hline Variable & Score (St. D.) \\
\hline Rating of selling popularity of skin care products on 4 points scale (mean \pm SD) & $2.83(1.23)$ \\
\hline Rating of selling popularity of hair care products on 4 points scale (mean \pm SD) & $2.51(0.84)$ \\
\hline Rating of selling popularity of cosmetic products on 4 points scale (mean $\pm S D$ ) & $2.33(0.96)$ \\
\hline $\begin{array}{l}\text { Rating of selling popularity of personal hygiene or toiletries products on } 4 \text { points } \\
\text { scale (mean } \pm \text { SD) }\end{array}$ & $2.33(1.30)$ \\
\hline
\end{tabular}

generic and brand names during dispensing process (79.5\%). Using 5 points Likert scale, respondents were asked to rate selling popularity of four types of cosmetic and personal care products namely, skin care products, hair care products, cosmetic products, and personal hygiene or toiletries products. All types have been rated average (average scores ranged from 2.33 to 2.83). Among them, the category rated highest was skin care products (average score $=2.83$, St.D. $=$ $1.23)$.

\section{Discussion}

Being involved in patients counseling adds an important value to pharmacists and increases their job satisfaction. Suleiman conducted a study in Riyadh to evaluate job satisfaction among community pharmacists [11]. Among findings was that pharmacists who dispensed a higher number of prescriptions and those 
who work with chain community pharmacies had had higher levels of satisfaction. This might be attributed to their feeling about the professional value of pharmacy and the important role pharmacists are playing as they are utilizing their knowledge and skills in serving their communities. Our sample of pharmacists reported a good level of job satisfaction, perceived their knowledge about cosmetic and personal care products to be high and rated their awareness about Saudi Food and Drug Authority (SFDA) regulations of "cosmetic and personal care products" to be high also. In addition, most of respondents in our sample declared undertaking courses about cosmetic and personal care products, and about half of them received more than 5 courses. Taking further education and on-job training would improve satisfaction further and enhance a pharmacist competence and confidence to provide counseling about cosmetic preparation and other medications. Pharmacists can keep their knowledge updated about current practice, new products, and trends via attending training courses, workshops, and conferences, and by reading articles from scientific journals, newsletters, and professional websites.

In a review about pharmacy practice in Saudi Arabia Al-jedai et al. judged patients counseling as a traditional role of community pharmacists in Saudi Arabia [12]. Almeman and Al-jedai considered cosmetics among four main sections in the community pharmacies in Saudi Arabia [13]. In the same context, most of the respondents in our study considered customers/patients counseling on cosmetics and personal care products as important. They were highly supportive of the statement "customers/patients are willing to listen to the counseling about their products" and the statement "pharmacists must keep in developing their communication skills with customers/patients". However, they were not supportive of the statement saying, "selling cosmetics and personal care products in other places than community pharmacies". Such findings indicate an excellent attitudes and views of pharmacists about their professional role as controllers of cosmetic and beauty products. In this regard, the study by Almeman reported significant variability among pharmacists in Saudi Arabia regarding the understanding and practice of whitening cosmeceuticals [8].

Most of pharmacists communicate with customers/patients directly via face-to-face, serve daily more than 100 customers/patients, and substantial proportion of them is asked for cosmetic or personal care products. Most of respondents ask the customers/patients if they have sensitivity from any components in the product and use both generic and brand names during dispensing process. Al Latif et al. reported findings of a study from the Eastern region of Saudi Arabia and mentioned that community pharmacist counseled their patients most of the times compared with sometimes for hospital pharmacists [14]. Such study reported lack of education and privacy along with impatient behavior of patients as common barriers hindering the provision of services in community pharmacy settings. On the other hand, our respondents rated the selling popularity of skin care products, hair care products, cosmetic products, and personal 
hygiene or toiletries products as average. Among them, the category rated highest was skin care products.

\section{Conclusion}

In conclusion, most of the community pharmacists surveyed in this study reported a good perceived knowledge and attitudes and demonstrated an acceptable level of practices regarding beauty products. SFDA is encouraged to adopt good pharmacy practice standards and guidelines to improve current practice of community pharmacists concerning beauty products. Continuous educational programs are needed for community pharmacists to enhance their knowledge and practice regarding beauty products. Policy makers are encouraged to consider making cosmetic courses obligatory for community pharmacists as part of continuing professional development programs required for licensing renewal.

\section{Conflicts of Interest}

The authors declare no conflicts of interest regarding the publication of this paper.

\section{References}

[1] Smith, M., Bates, D.W., Bodenheimer, T. and Cleary, P.D. (2010) Why Pharmacists belong in the Medical Home. Health Affairs, 29, 906-913. https://doi.org/10.1377/hlthaff.2010.0209

[2] Alhaddad, M.S. (2019) Youth Experience with Community Pharmacy Services and Their Perceptions toward Implementation of Medication Therapy Management Services by Community Pharmacists in the Western Region of Saudi Arabia. The rapeutic Innovation \& Regulatory Science, 53, 95-99.

[3] Gillani, S.W., Rahman, S A.U., Mohammad Abdul, M.I. and Sulaiman, S.A.S. (2017) Assessment of Community Pharmacists' Perceptions of Healthcare Services in Saudi Arabia. Journal of Pharmaceutical Health Services Research, 8, 269-274. https://doi.org/10.1111/jphs.12183

[4] Al-Aqeel, S.A., Al-Sabhan, J.F. and Sultan, N.Y. (2013) Analysis of Written Advertising Material Distributed through Community Pharmacies in Riyadh, Saudi Arabia. Pharmacy Practice, 11, 138-143? https://doi.org/10.4321/S1886-36552013000300003

[5] Alaqeel, S. and Abanmy, N.O. (2015) Counselling Practices in Community Pharmacies in Riyadh, Saudi Arabia: A Cross-Sectional Study. BMC Health Services Research, 15, 557. https://doi.org/10.1186/s12913-015-1220-6

[6] Alfadl, A.A., Alrasheedy, A.A. and Alhassun, M.S. (2018) Evaluation of Medication Counseling Practice at Community Pharmacies in Qassim Region, Saudi Arabia. Saudi Pharmaceutical Journal, 26, 258-262. https://doi.org/10.1016/j.jsps.2017.12.002

[7] Rasheed, M.K., Hasan, S.S. and Babar, Z.U.D. (2019) Community Pharmacist's Knowledge, Attitude, Roles and Practices Towards Patient-centred Care in Saudi Arabia: A Systematic Review of the Literature. Journal of Pharmaceutical Health Services Research, 10, 101-115. https://doi.org/10.1111/jphs.12264

[8] Almeman, A.A. (2020) Knowledge about and Attitude toward Cosmeceuticals 
among Pharmacists in Saudi Arabia. Journal of Cosmetic Dermatology, 19, 1-7.

[9] Ghiasi, G., Hashemian, F., Kebriaeezadeh, A. and Ghiasi, S. (2016) The Knowledge of Pharmacists about Cosmetics in Pharmacies of Tehran, Iran. Journal of Pharmacoeconomics and Pharmaceutical Management, 2, 34-37.

[10] AlRuthia, Y., Alsenaidy, M.A., Alrabiah, H.K., AlMuhaisen, A. and Alshehri, M. (2018). The Status of Licensed Pharmacy Workforce in Saudi Arabia: A 2030 Economic Vision Perspective. Human Resources for Health, 16, 1-8.

https://doi.org/10.1186/s12960-018-0294-8

[11] Suleiman, A.K. (2015) Stress and Job Satisfaction among Pharmacists in Riyadh, Saudi Arabia. Saudi Journal of Medicine and Medical Sciences, 3, 213.

https://doi.org/10.4103/1658-631X.162025

[12] Al-jedai, A., Qaisi, S. and Al-meman, A. (2016) Pharmacy Practice and the Health Care System in Saudi Arabia. The Canadian Journal of Hospital Pharmacy, 69, 231. https://doi.org/10.4212/cjhp.v69i3.1561

[13] Almeman, A. and Al-jedai, A. (2016) Pharmacy Practice in the Kingdom of Saudi Arabia. In: Fathelrahman, A.I., Mohamed Ibrahim, M.I., Wertheimer, A., Eds., Pharmacy Practice in Developing Countries. Academic Press, 171-197.

https://doi.org/10.1016/B978-0-12-801714-2.00009-5

[14] Al Laif, F.Z., Ahmad, R., Naqvi, A.A. and Ahmad, N. (2017) Pharmacist Perceived Barriers to Patient Counseling: A Study in Eastern Region of Saudi Arabia. Journal of Pharmaceutical Research International, 19, 1-12.

https://doi.org/10.9734/JPRI/2017/37705 